\title{
How Well-Informed Are Pension Scheme Members on Their Future Pension Benefits? Evidence from Ireland
}

\section{Alan Barrett, Irene Mosca \& Brendan Whelan}

To cite this article: Alan Barrett, Irene Mosca \& Brendan Whelan (2015) How Well-Informed Are Pension Scheme Members on Their Future Pension Benefits? Evidence from Ireland, Journal of Aging \& Social Policy, 27:4, 295-313, DOI: 10.1080/08959420.2015.1044817

To link to this article: https://doi.org/10.1080/08959420.2015.1044817 Jul 2015. Published online: 06 Oct 2015.

Submit your article to this journal $₫$

Џ Article views: 479

View Crossmark data $\complement$

Citing articles: 4 View citing articles 5 


\title{
How Well-Informed Are Pension Scheme Members on Their Future Pension Benefits? Evidence from Ireland
}

\author{
ALAN BARRETT, PhD \\ Research Professor, Economic and Social Research Institute, Dublin, Ireland \\ IRENE MOSCA, PhD \\ Research Fellow, The Irish Longitudinal Study on Ageing, Trinity College, and Economic and \\ Social Research Institute, Dublin, Ireland \\ BRENDAN WHELAN, MSC \\ Former Research Director, The Irish Longitudinal Study on Ageing, Trinity College, and \\ Economic and Social Research Institute, Dublin, Ireland

\begin{abstract}
One part of the policy response in many countries to increasing pension coverage will be greater private provision on the part of individuals. This requires that individuals are well informed about pensions. In this article, we assess levels of knowledge of pensions using a representative sample of older Irish adults. We find that two-thirds of individuals enrolled in pension schemes do not know what amount will be paid out on retirement and/or whether the payments will be in the form of lump sums, monthly payments, or both. One policy implication is the need for increased information to be directed at certain groups, in particular, women and less educated people. More fundamentally, the results suggest that the mandatory elements in pension systems should be extended.
\end{abstract}

KEYWORDS knowledge, older workers, pensions

\section{INTRODUCTION}

A major policy concern for many governments in Europe (and beyond) is how to ensure that national pension systems are both adequate and

Received January 6, 2014; revised November 12, 2014; accepted December 3, 2014.

Address correspondence to Alan Barrett, PhD, Economic and Social Research Institute, Whitaker Square, Sir John Rogerson’s Quay, Dublin 2, Ireland. E-mail: alan.barrett@esri.ie 
financially sustainable. This concern has existed for a number of years with adequacy and sustainability being threatened by population aging. However, the global economic crisis of recent years has heightened concerns due to factors such as fiscal crises that affected many countries.

In countries such as Ireland and the United Kingdom, governments have tended to look to the private sector as the route to boost pension saving, typically through occupation-based pension plans. According to the OECD, "Voluntary private provision for old age will become increasingly important in a range of other countries as future public benefits have been cut back" (OECD, 2012, p. 24). In looking to the private system to play an enhanced role in pension provision, policy makers in Ireland, the United Kingdom, and elsewhere are looking to individuals to take greater roles in pensionrelated decisions, often through the schemes offered by employers. While participation in state pension schemes is mandatory for employees through social insurance contributions, participation in occupational schemes outside of the public sector is often voluntary, as is participation in other forms of private pension saving arrangements. Given this increased role for private and hence voluntary arrangements, a question arises over whether people are well equipped to make good decisions regarding their future pension needs.

According to simple economics models, rational and forward-looking individuals will make optimal decisions on intertemporal allocation of resources if they have perfect knowledge of the pension system. In reality, knowledge is often imperfect because the information required for decision making is extensive and the system is very complex, with various organizations contributing to the possible options available to people. There is substantial involvement by the state through the social welfare system, the pension regulatory system, and the taxation system. Employers are also involved through their sponsorship of occupational pension schemes, as are personal pension providers. This complexity poses significant problems and difficulties for those planning for retirement. The knowledge and understanding of the system that individuals accumulate depend on a number of factors including the quantity/quality of information acquired at the workplace and from family members and peers, personal analytical abilities, and personal rate of time preferences (discount rates, myopia).

In this paper, we aim to explore the levels and patterns of knowledge of a private pensions system. We use the first wave of The Irish Longitudinal Study on Ageing (TILDA), which is a nationally representative study of people aged 50+ residing in Ireland. This data set is particularly well suited for our analysis because it includes a module on retirement planning. Respondents are asked a battery of questions about their pension arrangements, including questions on the form that future pension will be paid and the likely amount. When asked, participants are given the option of providing a response of "don't know." 
We investigate the level of "don't know" responses and also the characteristics of those who give "don't know" responses when asked about the form in which their supplementary pensions will be paid and/or how much these pensions will pay out on retirement. We find that around two-thirds of individuals who are making supplementary contributions are not able to estimate the form and/or amount of their pension benefits in retirement. Imperfect knowledge is higher for those who are poorly educated, female, younger, and living in rural areas. In terms of policy conclusions, the remarkably high numbers of "don't know" suggest that caution should be exercised by governments that plan on following Ireland and the United Kingdom in relying more heavily on voluntary private pension arrangement.

The paper is structured as follows: We first highlight the key features of Ireland's pension system and discuss the literature in this area. We then describe the data, outline the model employed in the analysis, and report the results. Finally, we provide some conclusions.

\section{THE IRISH PENSION SYSTEM}

The Irish pension system is composed of three basic pillars. The first pillar is the state social welfare system that provides a range of payments such as the State Pension. Entitlement to these payments is based either on contributions collected through the Pay-Related Social Insurance system or on a means test. The second pillar is occupational pensions, that is, pension schemes organized by employers as a service to their employees. These vary considerably in their organization and benefits. About one-third of occupational scheme members are in a defined contribution (DC) scheme, while two-thirds are covered by a defined-benefit (DB) basis. ${ }^{1}$ The quality of these schemes also varies in terms, for instance, of the size of the pension promised and the manner in which it is indexed. The pensions provided for workers in the public sector are distinctive in that in most cases they operate on a "pay as you go" basis and tend to be more generous than the private sector schemes.

The third pillar covers personal pensions, that is, pensions arranged by individuals on their own behalf through a pension provider. A new type of personal pension called a personal retirement savings account (PRSA) was introduced in 2002 to encourage more people to make individual provision for retirement. Employers who do not provide staff with an occupational pension are obliged to offer them the option of a PRSA arranged through the firm.

Under pension legislation in Ireland, there are regulations setting out the information that must be sent annually to members of both DC and DB systems. The majority of these regulations is contained in the Occupational Pension Schemes (Disclosure of Information) Regulations, 2006, and comprehensive guidance notes are provided by the state's pension regulator 
(Pensions Board, 2012). Under these regulations, there is a requirement to provide estimates of monthly payments that scheme members will receive upon retirement. In the case of DC schemes, the estimate is based on assumed rates of fund growth and future contributions. Compliance with these regulations is essentially universal. This is an important point because it shows that people are provided with details of their pensions, whether DB or DC. Hence, any lack of knowledge on their part results from a failure to engage with the information being provided.

\section{LITERATURE REVIEW}

A first strand of the literature has investigated the extent to which older individuals plan for their retirement. Using data from the Health and Retirement Study in the United States, Gustman and Steinmeier (2005) investigated knowledge about future pension benefits by comparing respondent reports with benefits calculated from Social Security records and employer pension plan descriptions. They found that around half of respondents were unable to report their expected pension benefits. Also, only half of those who reported a figure reported a value that fell within $25 \%$ of the measure calculated from Social Security records and employer pension plan descriptions. The authors also found that those who were least likely to know about their future pension benefits were poorly educated, women, and Black. On the other hand, those who had spoken with friends about retirement, were selfreported to be in poor health, and belonged to the top deciles of the earnings distribution were more likely to have better information about their future pensions.

More recently, Crawford and Tetlow (2012) investigated knowledge about future pension benefits among older English individuals using data from the English Longitudinal Study on Ageing. They found that over half of individuals aged 50 to 64 who were not yet retired at the time of interview had never thought about how many years of retirement they might need to finance. Crawford and Tetlow (2012) also found that only half of private pension scheme holders were able to report the exact amount they expected to get at retirement. This figure was higher for DB scheme holders (59\%) than for DC scheme holders (45\%). The authors highlighted that these figures might have overstated individuals' knowledge because respondents were advised to get out any paperwork they had relating to their finances, including statements from pension schemes.

Another strand of the literature has investigated the extent to which individuals can estimate with precision replacement rates, that is, the expected ratio of the first pension to the last (permanent) salary. For example, Maunu (2007) used information from a question taken from the 2005 wave of the Finnish Household Wealth Survey in which respondents were asked 
to estimate the monthly amount of old-age pension they were expecting to receive at the time of retirement. Maunu (2007) expected most informed individuals to know that the target level of pension benefits was around $60 \%$ of their earnings, which is a rule of thumb in the Finnish system. The author found that, although variation was high, most individuals did expect to get a replacement rate near 60\%. In a similar paper, Bottazzi, Jappelli, and Padula (2006) found that in the 1990s and early 2000s the expectation errors with respect to replacement rates of Italian workers were overall small (in the range of 3\%) and lower for individuals who were older, more experienced, and working in the public sector. It is worth noting that the papers by Maunu (2007) and Bottazzi and colleagues (2006) focused on expectations of replacement rates based on old-age pensions and not on occupational and private pensions. For obvious reasons, this reduces the degree of uncertainty in individuals' expectations.

A final strand of the literature has investigated how financial literacy affects planning for retirement, and evidence has been collected in the United States, England, the Netherlands, Italy, Germany, Sweden, Japan, New Zealand, Russia, and Europe as a whole (Alessie, Van Rooij, \& Lusardi, 2011; Almenberg \& Säve-Söderbergh, 2011; Banks \& Oldfield, 2007; BucherKoenen \& Lusardi, 2011; Christelis, Jappelli, \& Padula, 2010; Crossan, Feslier, \& Hurnard, 2011; Fornero \& Monticone, 2011; Klapper \& Panos, 2011; Lusardi \& Mitchell, 2011; Sekita, 2011). In the surveys employed in these empirical papers, financial literacy was measured by asking respondents to carry out elementary calculations related to concepts such as interest compounding, inflation, and risk diversification. These studies found that financial literacy and retirement planning are closely related and that there is a potentially important role for financial literacy in shaping retirement planning (Lusardi \& Mitchell, 2011, p. 503).

\section{DATA}

We use data from the first wave (2010) of TILDA, which is a nationally representative study of people aged $50+$ residing in Ireland. The study is closely harmonized with other leading international studies of aging such as The English Longitudinal Study of Ageing; the Survey of Health, Ageing, and Retirement in Europe; and the Health and Retirement Study in the United States.

Data collection in TILDA is made of three components: (1) a computeraided personal interview questionnaire; (2) a self-completion questionnaire, designed to explore certain areas considered particularly sensitive for respondents to answer directly to an interviewer; and (3) a comprehensive health assessment. A total of 8,504 individuals (8,175 aged 50+ and 329 younger partners of eligible individuals) were recruited at wave 1 , and a household response rate of $62 \%$ was achieved. 
TILDA includes a module that deals with the arrangements people are making to provide for their retirement. Private and public sector employees are asked whether they are (1) members of an occupational pension scheme organized by their current employer; (2) members of a PRSA scheme organized through their employer (and not a member of an occupational pension scheme); (3) not a member of either type of scheme. They are also asked whether they currently pay into one or more private pension plans and whether they are entitled to any other pensions from previous employers. Individuals who are self-employed, unemployed, or inactive (excluding retirees) are first asked whether they currently pay into a PRSA. They are then asked whether they currently pay into one or more private pension plans and whether they are entitled to any other pensions from previous employers.

Individuals seem to know whether they are currently paying into one or more occupational or private pensions or not. Fifty-seven percent of employees are members of an occupational pension or PRSA organized through their current employer; $41.8 \%$ are not members of either type of scheme; $1.1 \%$ report that they do not know; and $0.1 \%$ refuse to answer the question. Similarly, 6\% of those who are self-employed, unemployed, or inactive are currently paying into a PRSA; $93.5 \%$ are not paying into such a scheme; $0.3 \%$ does not know; and $0.2 \%$ refuses to answer this question.

Respondents who report that they are contributing to at least one of these pensions are then asked a series of questions on the detailed provisions of the scheme. For example, individuals are asked about their current contributions to the scheme, the contributions made by their employers, and the earliest age the pension plan allows them to retire. If they are contributing to more than one pension, they are asked about each pension separately. Respondents are given the option to refuse to answer or to say that they "do not know."

In the analysis below, we use the "don't know" responses as an indicator of a lack of knowledge regarding the parameters of pension schemes in which the respondents are enrolled. We focus on the questions regarding the form in which the pension will be paid (lump sum and/or regular payment) and how much the pension will pay out on retirement. When answering the question about the amount to be paid, respondents are allowed to provide either a euro amount or to express their expected payment as a percentage of salary.

In the case of some questions on pension-related matters, respondents are encouraged by the interviewer to check their pay slips; this approach is taken, for example, when asking about the contributions they or their employers make. This is done in an attempt to collect reliable data on pension contributions. Given that we cannot distinguish between those who checked and did not check their payslips, we do not include the questions on contributions in our analysis. 
Although the full TILDA sample includes over 8,500 people, we are only looking at individuals who have not yet retired and who are covered by some form of occupational or private pension. For this reason, the number of observations used here is just under 2,000.

\section{THE MODEL}

Our interest is in exploring whether people are informed about the parameters of their pension schemes and how knowledge varies across different people with different characteristics. To pursue this, our dependent variable is equal to 1 if the individual provides a "don't know" response to a pension question and 0 otherwise. We then run probit regressions to see whether individual characteristics explain the distributions of "don't know."

The specific questions used to create the dependent variable are as follows: Respondents are asked to answer the following questions in relation to the expected benefits of the occupational/personal pensions to which they are contributing:

- Question 1: When you retire, how will funds from your pensions be paid?

- As a pension only (go to Question 2)

- As a lump-sum plus a pension (go to Questions 2 and 3)

- Do not know

- Refused

If respondents know how funds will be paid, they are then routed to one (or both) of the following questions:

- Question 2: When you retire, before any tax deductions, how much do you expect to receive each month from this pension?

- Percentage of salary

- Monthly amount

- Do not know

- Refused

- Question 3: How much do you expect to receive as a lump sum payment from this pension scheme when you retire?

- Amount

- Do not know

- Refused

In our first probit model (Model 1), the dependent variable is equal to 1 if the respondent does not know the form and/or amount of her/his future pension benefits, 0 otherwise. This occurs when the respondent answers 
"do not know" to any of the three questions reported above. In our second probit model (Model 2), the dependent variable is restricted somewhat as it is based on responses to Question 2 only and is equal to 1 if the respondent cannot estimate his/her future monthly pension benefits, 0 otherwise. The share of individuals who refuse to answer Questions 1, 2, or 3 is negligible. We assign them to the base category assuming that they know the answer to the question(s) but refuse to report it. We first include individuals at work (employees and self-employed), in unemployment, or inactive. We then restrict our sample to employees only.

If respondents have more than one pension and cannot estimate the form/amount of at least one of the pensions, they are assigned to the "do not know" category. This is based on the assumption that if they do not know the expected benefits of at least one pension, they are not able fully to estimate the resources they will have in retirement. As a robustness check, we also estimate a model based on knowledge of the "most important" pension only. Results (not reported but available on request) are in line with those reported in the main model(s).

Turning to the explanatory variables, in the models including all respondents covered by at least one occupational/private pension, we follow the literature and control for:

- Current socioeconomic characteristics: single year of age; gender; marital status (married/cohabiting or not); highest qualification attained (none/primary, secondary, tertiary); geographic location (Dublin, urban outside Dublin, rural); labor market status (private sector employee, public sector employee, self-employed [farmer], self-employed [non-farmer], other [unemployed, permanently sick or disabled, looking after home, in education or training, or other]); number of pensions the individual is covered by; number of children; and number of years spent working over the lifetime.

- Socioeconomic characteristics in childhood: whether both respondents' parents were working outside the home when the respondent was younger than age 14 (yes or no).

- Health: self-reported health (excellent/very good, good, fair/poor); health insurance (yes or no).

- Cognitive ability: word recall test in which 10 common words are presented orally and the respondent is asked to remember them after a short delay.

If the results of the international literature are confirmed, we would expect poorer knowledge among women and poorly educated individuals. We would also expect better knowledge among those who have spent a higher proportion of their lives at work and who are older, as they are 
closer to retirement and, hence, closer to the point in which they will stop contributing and receive the pension benefit instead. We include our (limited) measure of cognitive ability because of the findings in previous studies of links between cognition and general financial knowledge. We also include a measure of health status on the expectation that people in poorer health may pay closer attention to financial planning.

In the models focusing on employees only we also control for:

- Socioeconomic group: managers/professionals, non-manual, manual skilled, semi-skilled, unskilled, unknown, or refused.

- Type of pension the individual is covered by: DB, DC, other (if individual is covered by a pension with a previous employer or a private pension or is unsure).

- Part-time employment (yes or no).

- Firm size (1-24, 25-199, 200+ employees).

Once again, if the results of the international literature are confirmed, we would expect full-time employees and employees in higher socioeconomic groups to be better informed.

\section{RESULTS}

\section{Descriptive Statistics}

Table 1 summarizes the descriptive statistics. The first row of Table 1 shows that $67.7 \%$ of respondents (and $68.2 \%$ of employees) do not know either the form of payment or the amount (or both) of their future benefits. Also, 55.8\% of respondents (and 56.3\% of employees) do not know their future monthly pension benefits.

These figures are striking and one possible explanation that might suggest itself is that the data were collected during the economic crisis when uncertainty was high. While there might be some truth in this, a closer look at the proportion of people in the "don't know" category who are in DB schemes is revealing. According to Table 1, $50 \%$ of those covered by a DB pension do not know the amount they will receive, even as a percentage of salary. Given that DB should be the least uncertain and most transparent scheme, it would seem that the lack of knowledge is not limited to those in DC or other schemes.

Looking more broadly at Table 1 , we can see the characteristics of those who are more likely to have imperfect knowledge. For dichotomous variables, statistically significant differences are reported for each subgroup with respect to the category omitted in the econometric model, which is the reference category. For continuous variables, we report the mean value for 


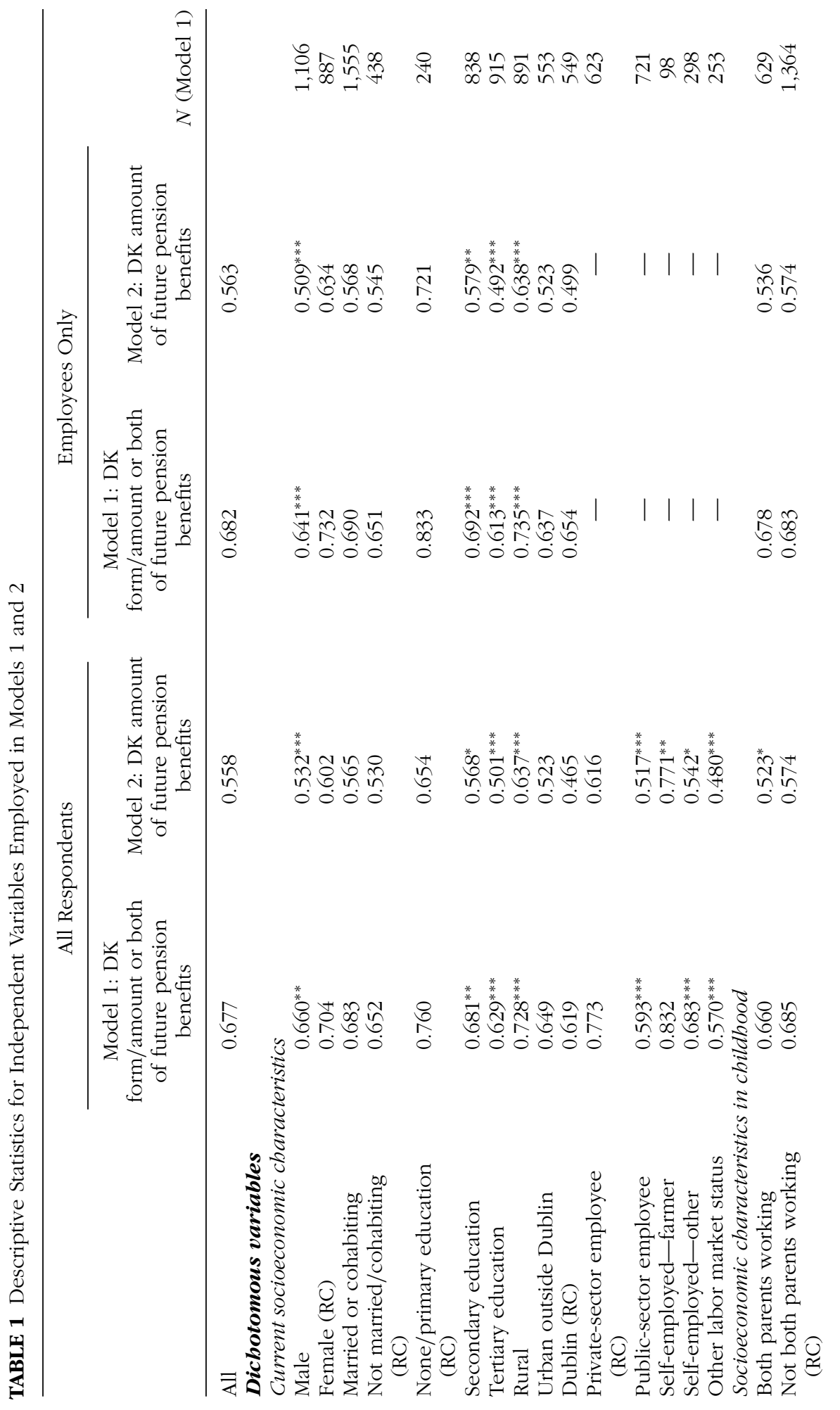




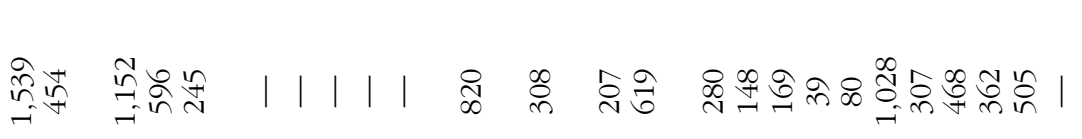

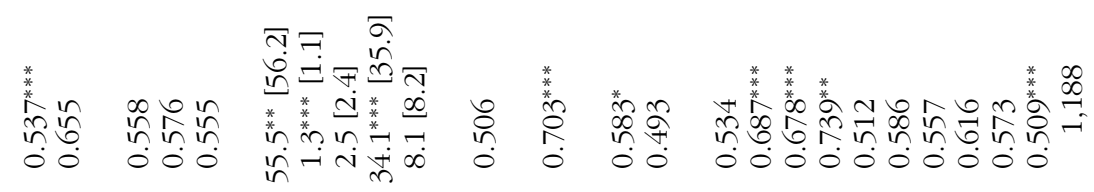

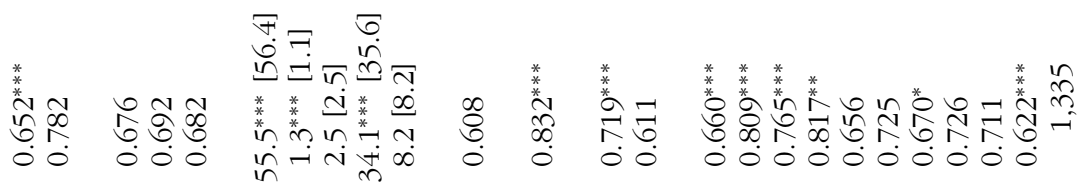

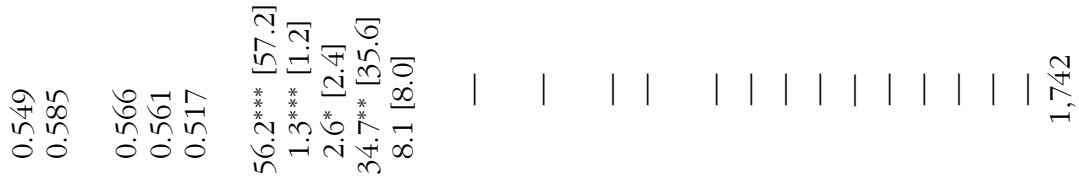

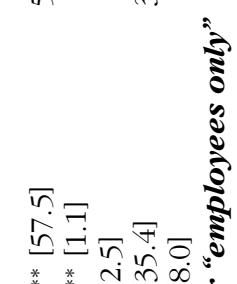

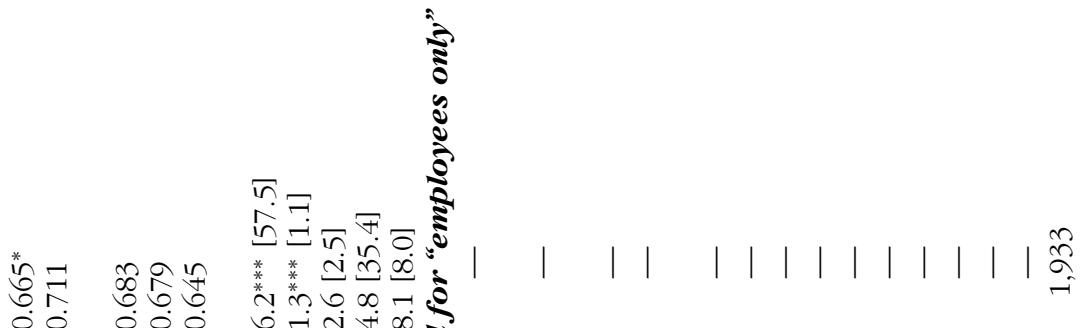

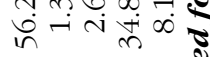

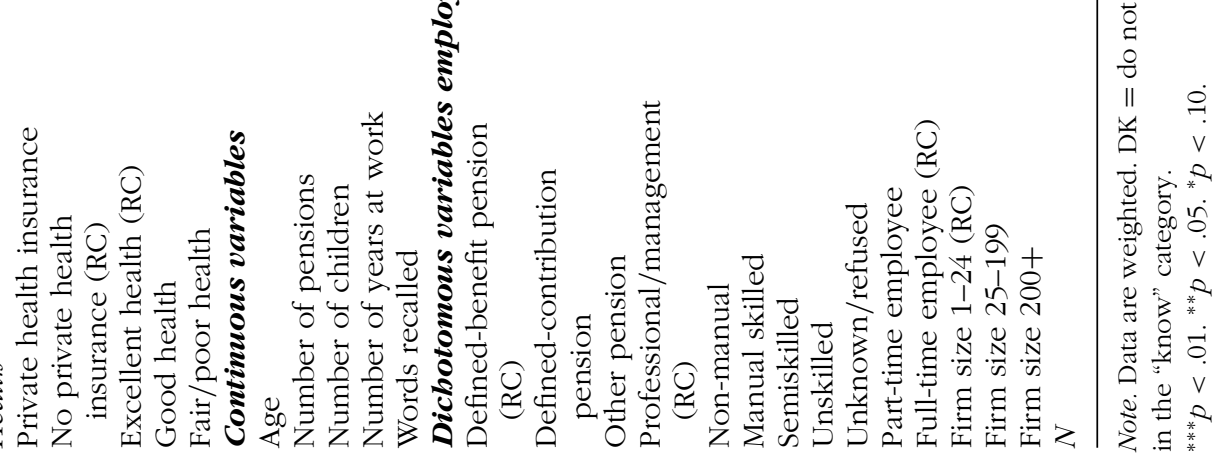


those falling into the "do not know" category and, in square brackets, the mean value for those falling into the "know" category. Statistically significant differences in means between the two groups are reported.

In line with other studies (for example, Banks \& Oldfield, 2007; Gustman \& Steinmeier, 2005), we find that younger individuals (those closer to age 50 , which is the cutoff in TILDA), women, and poorly educated individuals are less likely to know about future benefits. Just over $70 \%$ of women and $76 \%$ of those with primary or no education cannot estimate either the form or the amount (or both) of their future benefits, compared to 66\% of men and $62.9 \%$ of those with tertiary education. Also, "imperfect knowledge" is highest among those living in rural areas and for farmers. The share of those with imperfect knowledge is lower for those falling into "other labor market status" than for employees or self-employed. This is probably because those who have already withdrawn from the labor market or are unlikely to return-for example homemakers and permanently sick and disabled people-are more informed about their future pension benefits.

When focusing on employees only, we observe a clear gradient for socioeconomic group. Managers/professionals are at lowest risk of imperfect knowledge, unskilled workers at highest. Also, the degree of imperfect knowledge is significantly lower for those covered by a DB pension. This is to be expected, although as noted above the level of "don't know" responses among those covered by DB schemes is still surprisingly high.

\section{Regression Results}

Table 2 presents results from probit models exploring the relation between respondents' imperfect knowledge of the form/amount of their future pension benefits and the set of independent variables listed above. The dependent variable in columns 1 and 3 takes on a value of 1 if the individual answers "do not know" to any of the three questions outlined above. The dependent variable in columns 2 and 4 takes on a value of 1 if the individual answers "do not know" to question 2 (model 2). Columns 1 and 2 focus on all respondents, columns 3 and 4 on employees only. Marginal effects and $p$ values are reported in the table.

The results of columns 1 and 2 show that the probability of having imperfect knowledge of future pension benefits is lower for individuals who are older, are male, have a secondary or tertiary level of education, currently work in the public sector, and are self-employed (other than farming) or in the "other" category of labor market status. Another predictor of lower rates of imperfect knowledge is having grown up in a family in which both parents were working. We assume that this variable captures something about the environment in dual-income homes, when the TILDA respondents were young, where issues related to work may have been discussed more often. Those covered by private health insurance also show a lower probability of 


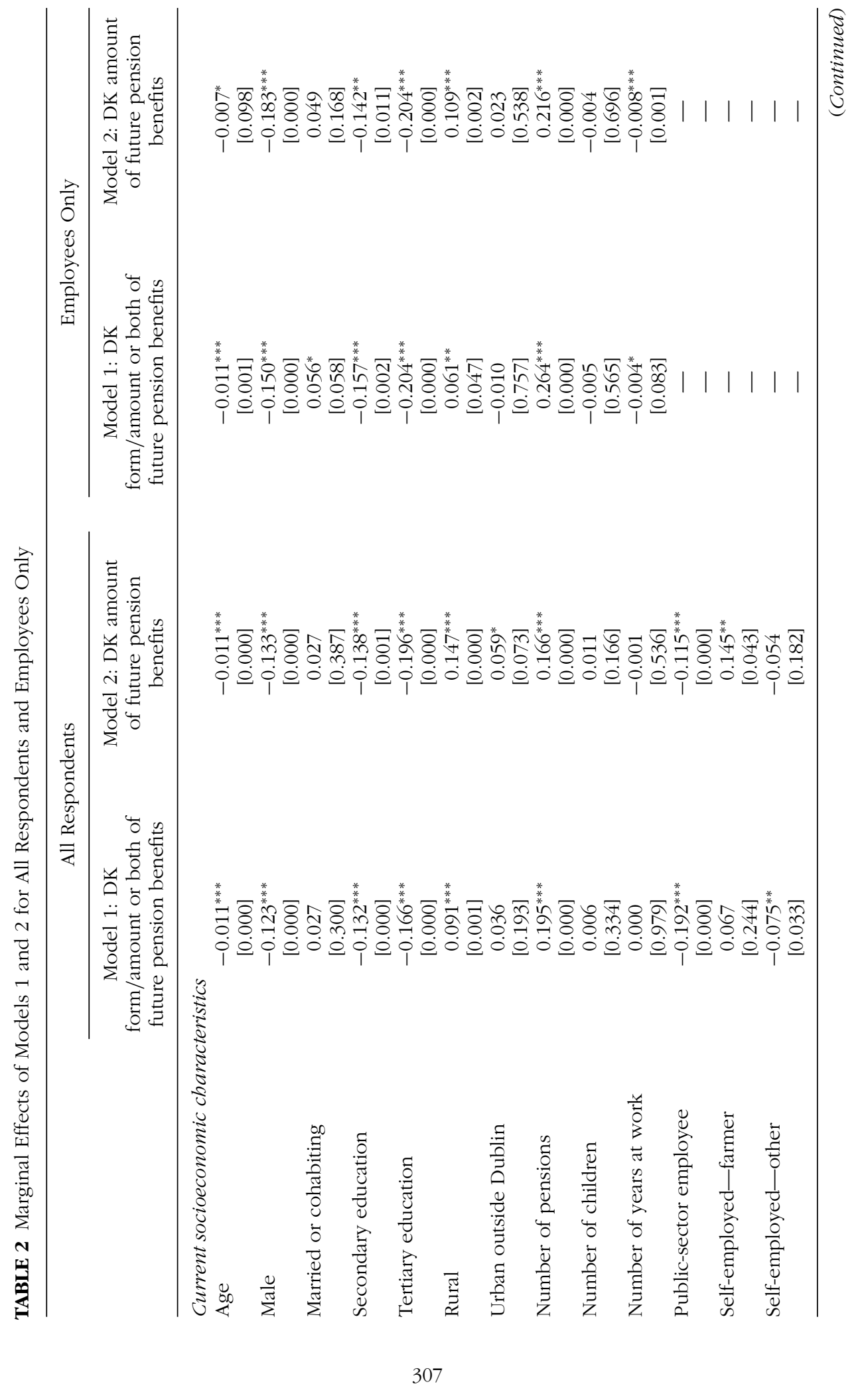




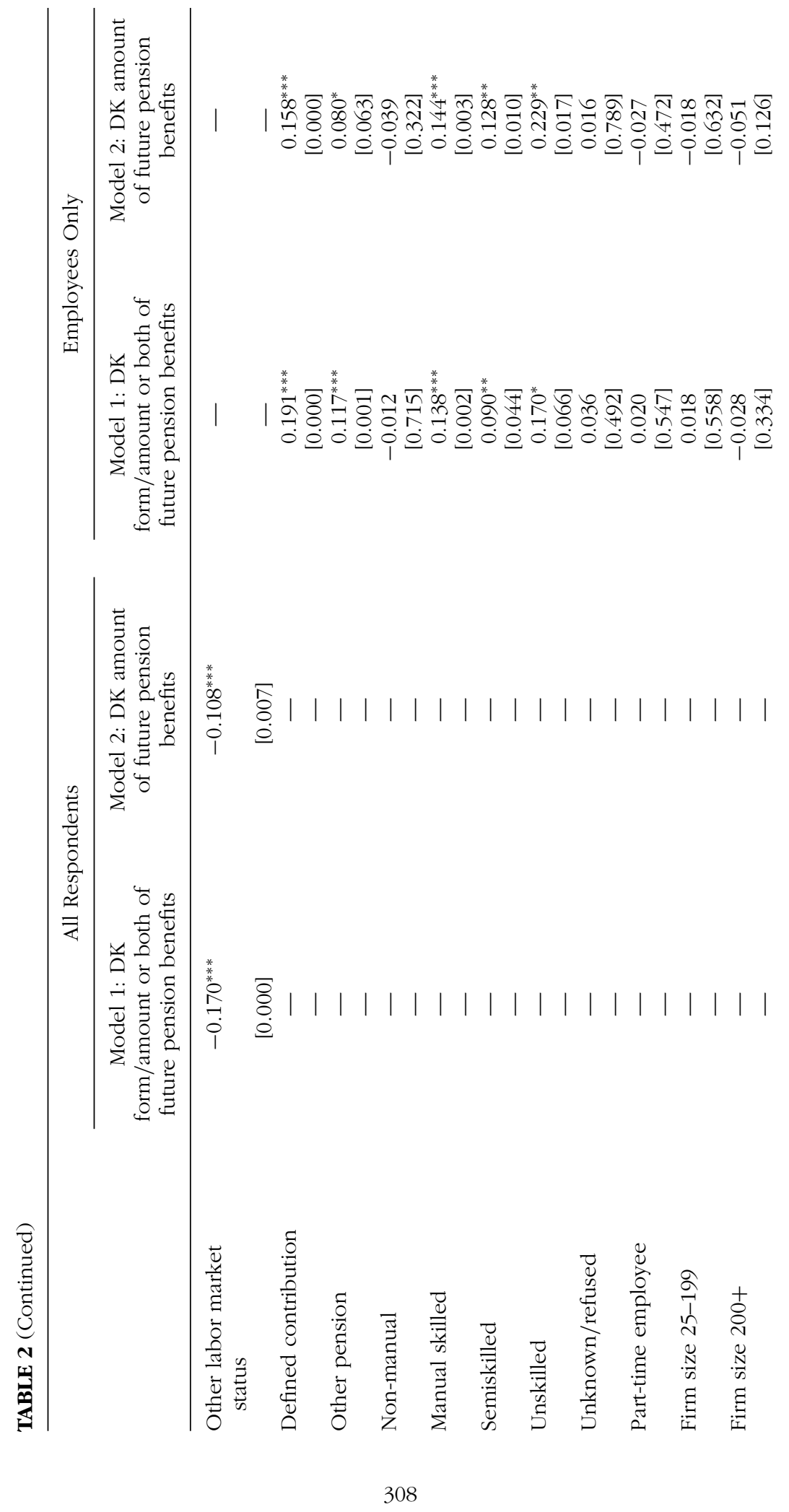




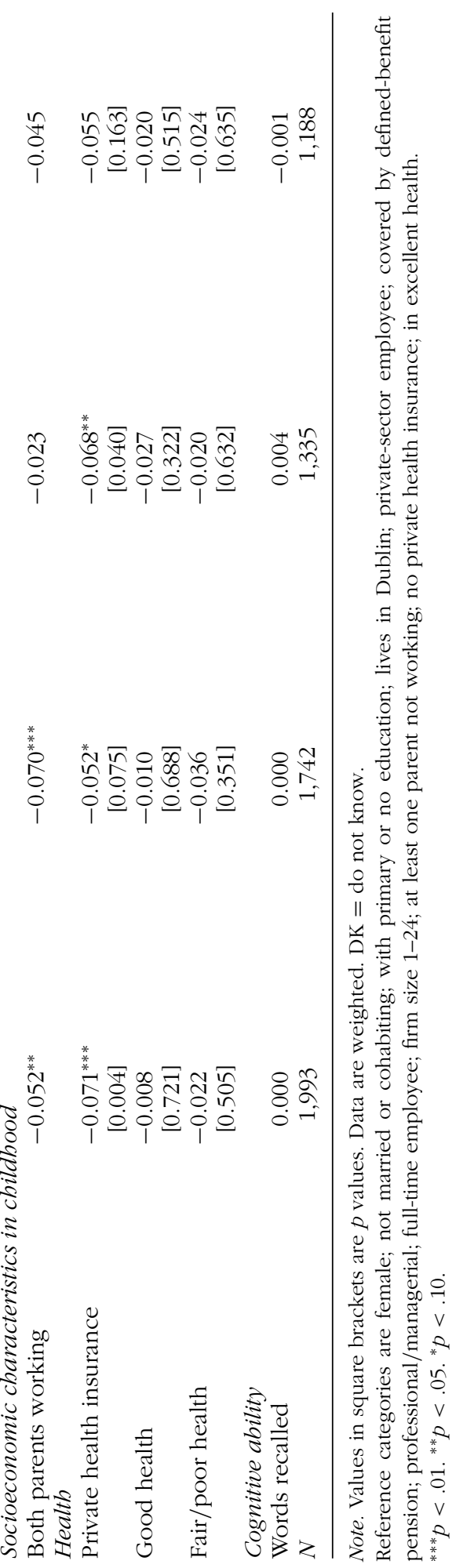


having imperfect information. Here, we assume that having private health insurance is an indicator of individuals who make careful decisions about their finances and their futures.

The results are generally in line with those of the international literature and with our initial assumptions. In particular, we observe a clear educational gradient with individuals with secondary (tertiary) education being $13.2 \%(16.6 \%)$ points less likely to have imperfect knowledge about the form/amount (or both) of their future pension benefits. Those living in rural areas and covered by a higher number of occupational/personal pensions are more likely to have imperfect knowledge. Respondents who can recall a higher number of words in the recall test do not seem to have better knowledge. This is somewhat surprising because we expected a link between this measure of cognitive ability and knowledge of pension parameters.

The results of columns 3 and 4 show that employees who are older, are male, have secondary or tertiary levels of education, and are covered by private health insurance are less likely to have imperfect knowledge of their future benefits. We observe a clear gradient in socioeconomic status: the probability of not being able to estimate the monthly amount of future pension benefits is $22.9 \%$ points higher for unskilled workers than for managers and professionals. Also, individuals covered by DC pensions are $15.8 \%$ points more likely to have imperfect knowledge of the monthly amounts of their future pension benefits than those covered by a DB pension. ${ }^{2}$

\section{CONCLUSIONS}

The lack of knowledge that has been uncovered of the basic parameters of the pension plans in which people are enrolled is striking. Recalling that the analysis is based on people older than 50 who are covered by some sort of plan, it seems reasonable to assert that pension-related knowledge should be higher in this group compared to others in the population. If this is the case, then levels of knowledge in the remainder of the population would be even lower. It is against this background that the Irish government, like others, will place a greater onus on individuals to make provision for their retirements.

As we have identified an information problem, the most straightforward policy proposal would be for the state to provide more information. The results in this paper suggest how some groups might be targeted. There is evidence that women are less well-informed than men and that there are socioeconomic gradients, whether we use education or occupation as the indicator of socioeconomic status.

On the question of how best to provide information, a number of studies in the United States have investigated whether financial education provided 
in the workplace can increase retirement saving and alter the investment allocation of assets in retirement accounts (Bayer, Bernheim, \& Scholz, 1996; Bernheim \& Garrett, 2003; Clark, d'Ambrosio, McDermed, \& Sawant, 2006; Clark \& Schieber, 1998; Madrian \& Shea, 2001). The findings of these studies are quite encouraging: They show that workers employed by firms that offer financial education programs have higher participation rates and contribution rates in DC plans (Bayer et al., 1996; Clark \& Schieber, 1998) and greater diversification in their retirement plan portfolios (Madrian \& Shea, 2001). Clark and colleagues (2006) found that women are more responsive to financial education programs carried out in the workplace and are more likely to raise their desired retirement ages, increase their target income replacement goals, and alter their savings behavior as a result of the financial education program. Bayer and colleagues (1996) showed that the effect is typically stronger for non-highly compensated employees, that seminars are the most effective type of communication, and that the effect is higher for those who attend the seminars more frequently.

While there may be scope to provide information and coaching, the question remains regarding whether pensions are an area where too great a reliance on individual decision making may lead to unfavorable outcomesfor individuals and for the state. In this context, policies that draw on a greater role for the private sector but also include elements of compulsion may be preferable to purely voluntary private arrangements. Some countries have experimented with a mild form of compulsion, notably through auto-enrollment in occupational pensions with the option to opt out. New Zealand has led the way in this regard and is being followed by the United Kingdom. The experience in New Zealand has been successful, and if this is mirrored in the United Kingdom, it may point the way for balancing individual responsibility for pension provision with a strong signal from the state on the desirability of making such provision.

\section{ACKNOWLEDGMENTS}

We thank one anonymous referee and the editor for their insightful comments. We also thank David Harney, Patrick Connell, and seminar participants at the Economic and Research Institute and TILDA. All errors are our own. TILDA is funded by the Irish Government Department of Health and Children, Atlantic Philanthropies, and Irish Life. Researchers interested in using TILDA data may access the data for free from the Irish Social Science Data Archive at University College Dublin (http://www.ucd.ie/issda/data/ tilda/) or the Interuniversity Consortium for Political and Social Research at the University of Michigan (http://www.icpsr.umich.edu/icpsrweb/ICPSR/ studies/34315). 


\section{NOTES}

1. DB schemes provide the employee with a pension "promise" of a certain percentage of an employee's final salary. DC schemes offer a pension determined by the level of contributions invested into a fund, its investment performance, and the charges levied.

2. As a final robustness check, we employ an additional model that focuses on imperfect knowledge of lump sums only. We assign the value of 1 to the dependent variable if the individual does not know how much she/he will receive as a lump sum when retired, 0 otherwise. Results are in line with those of the main models presented in the paper. For example, the probability of not knowing the amount of the lump sum is lower for individuals who are older, male, working in the public sector, and covered by private health insurance and higher for employees who are unskilled and covered by a DC pension. Results are available on request.

\section{REFERENCES}

Alessie, R., Van Rooij, M., \& Lusardi, A. (2011). Financial literacy and retirement preparation in the Netherlands. Journal of Pension Economics E Finance, 10(4), 527-545. doi:10.1017/S1474747211000461

Almenberg, J., \& Säve-Söderbergh, J. (2011). Financial literacy and retirement planning in Sweden. Journal of Pension Economics \& Finance, 10(4), 585-598. doi:10.1017/S1474747211000497

Banks, J., \& Oldfield, Z. (2007). Understanding pensions: Cognitive function, numerical ability and retirement saving. Fiscal Studies, 28(2), 143-170. doi:10.1111/fisc.2007.28.issue-2

Bayer, P., Bernheim, D., \& Scholz, K. (1996). The effects of financial education in the workplace: evidence from a survey of employers (Unpublished paper). Stanford University.

Bernheim, D., \& Garrett, D. M. (2003). The effects of financial education in the workplace: Evidence from a survey of households. Journal of Public Economics, 87, 1487-1519. doi:10.1016/S0047-2727(01)00184-0

Bottazzi, R., Jappelli, T., \& Padula, M. (2006). Retirement expectations, pension reforms, and their impact on private wealth accumulation. Journal of Public Economics, 90, 2187-2212. doi:10.1016/j.jpubeco.2006.03.005

Bucher-Koenen, T., \& Lusardi, A. (2011). Financial literacy and retirement planning in Germany. Journal of Pension Economics \& Finance, 10(4), 565-584. doi:10.1017/S1474747211000485

Christelis, D., Jappelli, T., \& Padula, M. (2010). Cognitive abilities and portfolio choice. European Economic Review, 54, 18-38. doi:10.1016/j.euroecorev.2009.04.001

Clark, R., \& Schieber, S. (1998). Factors affecting participation rates and contribution levels in 401(k) plans. In O. Mitchell, \& S. Schieber (Eds.), Living with defined contribution pensions (pp. 69-97). Philadelphia: University of Pennsylvania Press.

Clark, R. L., D’ambrosio, M. B., McDermed, A. A., \& Sawant, K. (2006). Retirement plans and saving decisions: The role of information and education. Journal of Pension Economics and Finance, 5, 45-67. doi:10.1017/S1474747205002271 
Crawford, R., \& Tetlow, G. (2012). Expectations and experiences of retirement in defined contribution pensions: A study of older people in England (IFS report R73). London, United Kingdom: Institute for Fiscal Studies.

Crossan, D., Feslier, D., \& Hurnard, R. (2011). Financial literacy and retirement planning in New Zealand. Journal of Pension Economics E Finance, 10(4), 619-635. doi:10.1017/S1474747211000515

Fornero, E., \& Monticone, C. (2011). Financial literacy and pension plan participation in Italy. Journal of Pension Economics \& Finance, 10(4), 547-564. doi:10.1017/S1474747211000473

Gustman, A. L., \& Steinmeier, T. (2005). Imperfect knowledge of social security and pensions. Industrial Relations, 44(2), 373-395.

Klapper, L., \& Panos, G. A. (2011). Financial literacy and retirement planning: The Russian case. Journal of Pension Economics E Finance, 10(4), 599-618. doi: $10.1017 /$ S1474747211000503

Lusardi, A., \& Mitchell, O. S. (2011). Financial literacy around the world: An overview. Journal of Pension Economics and Finance, 10(4), 497-508. doi:10.1017/S1474747211000448

Madrian, B., \& Shea, D. (2001). Preaching to the converted and converting those taught: financial education in the workplace (Unpublished paper). University of Chicago.

Maunu, T. (2007). How well can individuals approaching retirement estimate their future pension benefits? Finnish Centre for Pensions Working Papers 2007, p. 2. Helsinki, Finland: Finnish Centre for Pensions.

OECD. (2012). Pensions outlook 2012. Paris, France: OECD.

Pensions Board. (2012). Disclosure of information by occupational pension schemes. Dublin, Ireland: Pensions Board.

Sekita, S. (2011). Financial literacy and retirement planning in Japan. Journal of Pension Economics \& Finance, 10(4), 637-656. doi:10.1017/S1474747211000527 